\title{
Adventures in Supercomputing: Scientific Exploration in an Era of Change
}

\author{
Edna Gentry \\ University of Alabama in Huntsville; Huntsville, AL 35899 \\ Barb Helland \\ Krell Institute; Ames, IA 50010 \\ Barbara Summers \\ Oak Ridge National Laboratory*; Oak Ridge, TN 37831 \\ RECEVED \\ Nov 0 \& 1997 \\ OSTI \\ * Managed by Lockheed Martin Energy Research Corporation, under contract DE-AC05-960R22464 for the US DOE
}

\begin{abstract}
Students deserve the opportunity to explore the world of science surrounding them. Therefore it is important that scientific exploration and investigation be a part of each student's educational career. The Department of Energy's Adventures in Supercomputing (AiS) takes students beyond mere scientific literacy to a rich embodiment of scientific exploration. AiS provides today's science and math students with a greater opportunity to investigate science problems, propose solutions, explore different methods of solving the problem, organize their work into a technical paper, and present their results.

Students learn at different rates and in different ways. Science classes with students having varying leaming styles and levels of achievement have always been a challenge for teachers. The AiS "hands-on, minds-on" project-based method of teaching science meets the challenge of this diversity head on! AiS uses the development of student chosen projects as the means of achieving a lifelong enthusiasm for scientific proficiency. One goal of AiS is to emulate the research that takes place in the everyday environment of scientists. Students work in teams and often collaborate with students nationwide. With the help of mentors from the academic and scientific community, students pose a problem in science, investigate possible solutions, design a mathematical and computational model for the problem, exercise the model to achieve results, and evaluate the implications of the results. The students then have the opportunity to present the project to their peers, teachers, and scientists. Using this inquiry-based technique, students learn more than science skills, they learn to reason and think -- going well beyond the National Science Education Standard [1]. The teacher becomes a resource person actively working together with the students in their quest for scientific knowledge.
\end{abstract}

\section{Introduction}

The primary goal of the Department of Energy's K-12 educational project, Adventures in Supercomputing (AiS), is to foster and enhance the participation of diverse populations of high school students in mathematics, science, and computing. Over the five year pilot period, AiS has evolved to encompass an interdisciplinary approach using the techniques of computational science. Computational science integrates the disciplines of mathematics, science, and engineering and utilizes computers, networking, and scientific visualization to simulate real-world problems. During the pilot project, AiS students from 70 high schools in five states--Alabama, Colorado, Iowa, New Mexico, and Tennessee--have completed over a thousand scientific investigations using computational science techniques and have developed computational simulations for a wide variety of problems including population growth, weather forecasting, energy consumption, ground water contamination, and tumor growth.

The AiS program embraces many of the ideals expressed in the National Science Education Standards and other educational reforms which have been proposed to engage student learners in effective learning with an emphasis on critical thinking, hands-on problem solving, and independent student research. In addition, a major component of AiS is the use of computing and networking technologies to improve teaching, facilitate learning, and overcome traditional barriers in the classroom.

\section{Background}

The Adventures in Supercomputing program is a derivative of an earlier pioneering program developed by Dr. John Ziebarth in Alabama [2]. As an extension to Ziebarth's program, the AiS coordinators defined a classroom environment that mimics the computing environment of a Department of Energy laboratory where K-12 students and teachers use an Internet connection and personal workstations to access shared central computers. Since AiS schools are required to maintain a computational science class, it is critical that schools have access to technical consultants who can assist in trouble-shooting and problem-solving and who are knowledgeable in the AiS program and curriculum. Some teachers in each state have received specialized training which enables them to assist fellow teachers in maintaining their local computational science environment. Additionally, technical support is provided by each state's sponsoring agency.
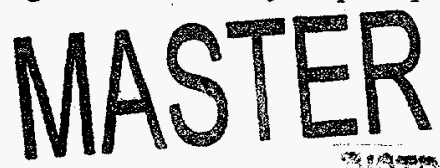

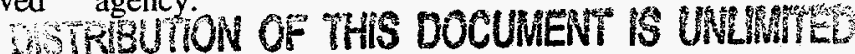
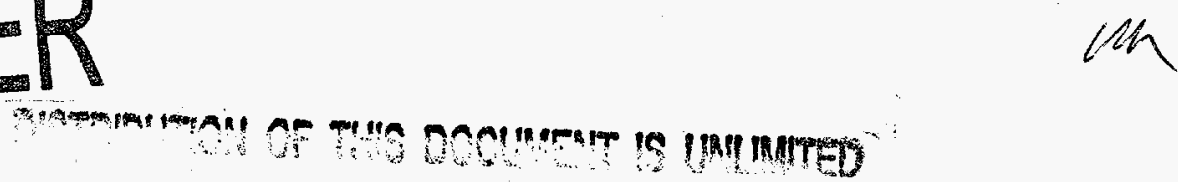


\section{DISCLAIMER}

This report was prepared as an account of work sponsored by an agency of the United States Government. Neither the United States Government nor any agency thereof, nor any of their employees, make any warranty, express or implied, or assumes any legal liability or responsibility for the accuracy, completeness, or usefulness of any information, apparatus, product, or process disclosed, or represents that its use would not infringe privately owned rights. Reference herein to any specific commercial product, process, or service by trade name, trademark, manufacturer, or otherwise does not necessarily constitute or imply its endorsement, recommendation, or favoring by the United States Government or any agency thereof. The views and opinions of authors expressed herein do not necessar. ily state or reflect those of the United States Government or any agency thereof. 


\section{DIsclamirx}

Portions of this docoment mey be illegible in electronic image products. Images are produced from the best available original docoment 
Teacher training modules were designed to support the teachers' professional development in the area of computational science and are in line with the National Science Education Standards guidelines for professional development and teaching science. For example, the modules for the AiS summer institute are focused around learner-centered project development. Computational science modules (programming, network resources, mathematical modeling, and scientific visualization) are introduced in the context of "mini-projects." More importantly, teachers form interdisciplinary teams and investigate a number of computational science projects of interest to them.

Another component of AiS is an on-going assessment of the program. Recognizing that the project-based AiS curriculum represented a shift from a teacher-centered to a learner-centered classroom, AiS project leaders sought an external assessment team that would employ project-based techniques using technology as an evaluation platform. Because the Center for Children and Technology (CCT) used these techniques, they were selected to assess the AiS program. Recommendations from the results of the yearly assessments were used to modify the teacher training modules [3,4].

In 1995, AiS coordinators formally packaged their summer institute as a set of materials available via the World Wide Web. The URL for the on-line textbook is: http://ais.cs.sandia.gov/AiS/textbook/textbook.html. The AiS on-line textbook articulates a curriculum that encourages students to work in teams, is learner-centered, and presents an interdisciplinary approach to scientific investigations through computational simulations of real-world problems. In other words, AiS embodies the goals and standards put forth in the National Science Education Standards.

\section{Project Development}

During the AiS Summer Institute, teachers experience the project development process. Teams of teachers develop several "mini-projects" to help them understand the scientific approach used to develop and complete projects. The teachers' background knowledge in science and mathematics coupled with the teaching strategies and project development experience gained in the Summer Institute provide them with tools to lead their students through an inquiry-based method of learning science.

A computational science project involves the use of the scientific method and computers to investigate and analyze real-world problems. Through an investigation of a scientific phenomenon, the student develops a mathematical model to explain the physical occurrence.

The first step in project development is selecting a topic. To do so, students explore several areas of interest to them through examination using all avenues of research World Wide Web, interviews with scientists, and library resources. Once a topic is selected, the students continue to do background investigations to narrow the focus and to gain a fuller understanding of the problem. Research becomes an integral and on-going component of the student project. For example, two Tennessee students combined their interest in motorcycle racing with a suggestion from their mentor and selected heat transfer through a motorcycle engine block as the topic of their project.

After the students have completed their background research, they pose their problem definition, transforming the topic into a scientific problem to be investigated and analyzed. This definition establishes an accurate and clear scope of the project and describes the characteristics, limitations, and applications of the problem. In the case of the heat transfer problem, the students narrowed the focus of their problem to the simulation of heat movement through the engine block of a 1986 Kawasaki motorcycle engine.

The next step in the project development process is to develop mathematical and computational models. This critical step is strengthened by students working together in teams, with the support of their teacher and by the assistance of knowledgeable professionals, such as engineers, researchers, professors, teachers, graduate students, and other community members, who serve as scientific mentors. The mathematical model serves as the basis for the computational model. In order to produce scientific results, the students employ various programming techniques to implement the computational model.

With the help of their mentor the students in the heat transfer project developed a mathematical model that divided the engine block into a $29 \times 29$ grid. Since Algebra II was the highest level mathematics course taken by either student on the team, they used the method of cellular automata and a difference equation to simulate the flow of heat through the engine block. The equation,

$$
e(r, c)=[e(r-1, c)+e(r+1, c)+e(r, c-1)+e(r, c+1)] 4
$$

calculates the value at each point on the grid. In the equation, $e$ represents the temperature of the engine, $r$ represents the rows in the engine block and $c$ represents the columns in the engine block. Using this mathematical model the students developed a computational model in FORTRAN that simulates the heat dissipation through the engine block. "The program assumed that the initial temperature of the engine block is set at 60 degrees Fahrenheit. The temperature of the cylinder is initialized at 700 degrees while the temperature of the water jacket surrounding the cylinder is placed at 60 degrees and not allowed to rise above 180 degrees. During the process of running the program, one hundred and forty-eight datafiles were created before the temperature of the block reached equilibrium." [5]

Like scientists, students analyze their results through data visualization techniques in order to gain a greater understanding of their results. A visual image is often very 
useful in detecting subtle differences and in identifying trends in data sets. Visualization of the data provides an avenue for data analysis and drawing conclusions. It is important that the students thoroughly understand the images they have produced and are able to explain them to their teacher or mentor. The students must also understand the implications of the data and be able to draw conclusions based on the actual results from their program. Only then can the student return to the original problem and offer a solution based on their results. In the heat flow problem previously described, an animated gif movie was created from a subset of the resulting datasets to represent the flow of heat through the engine. The URL for the project paper is: http:/www.krellinst.org/AiS/national. (Select National Expo in the left frame, select 1997 National Expo, and then listed by Tennessee select: "Application of Heat Transfer.")

Another vital element in an inquiry-based curriculum is communication. Through discussions with team members, mentors, and teachers, the students strengthen their written and oral communication skills. Specifically, upon completion of their work students provide a full description of their project in a technical paper containing the following elements: abstract-a brief overview or summary of the problem; introduction-including background material; problem description-a complete description of the problem to be solved; method of solution-a detailed description of the procedure used to solve the problem; results of the mathematical and computational models; and conclusions drawn from the results. Since the paper is limited to ten pages [the computer program is not included in the page restriction], the students must also employ their editorial skills.

Presentation skills are enhanced through the annual EXPO where students present the findings of their project. They prepare a technical display and present their project to computational scientists from the Department of Energy laboratories, industry, and education volunteer their time to serve as judges. Project judging takes place in two phases: 1) prior to the EXPO judges evaluate the technical papers, appraising the validity of the model, and the description of the problem; and 2) during the EXPO judges interview the students, asking them questions about all components of their project development. This completes the project development process as the students are able to share their work with others.

\section{Assessment}

The success of an inquiry-based project development process for learning science can be well documented through the AiS program. For the past four years CCT has conducted an assessment of the AiS program. Assessment of student learning was done using a videotape of each student, either individually or as a team member, presenting his/her project and answering questions about it. Questions were asked in regard to the project topic, mathematical model, computational model, implementation of these models, and the images and figures generated or displayed in their presentation materials. Students also discussed their algorithm and demonstrated a critical analysis of the problem. Students were required to explain in detail the model, including any restrictions, and the implications of their results, their conclusions, and the basis for drawing these conclusions.

Videotapes were analyzed to evaluate the quality of student performance with regard to the following criteria: understanding, critical thinking, clarity, teamwork, and technical competence. CCT reports that over three-fourths of the students interviewed and videotaped were able to create a well-defined project, present and explain it to the questioner, and answer specific questions about the project. They had a clear sense of their problem, how they solved the problem, and the conclusions they drew from the results obtained [4].

\section{Conclusions and Implications}

One of the main objectives of the AiS program is to bring the learning of science to a wide range of students - students of both genders, and students of diverse racial, ethnic and socio-economic background. AiS has successfully blended these students so that their gender and background do not determine their success in the program. As stated in the Final Report 1994-1995 from CCT, "AiS is reaching a range of students, of both genders, from different racial, ethnic and socio-economic backgrounds. These factors do not play a role in predicting student successes in the program." [4]

Science for all students is the foundation of the National Science Education Standards. The AiS coordinators are convinced that all students can learn science given the opportunity and have designed the AiS curriculum and teaching strategies so that all students are encouraged to participate and excel in the program. Ais has been, for the past five years, helping to bridge the gap that exists between female and minority students and success in technical courses and overcome the inadequacies of traditional programs by providing alternative opportunities for learning and achievement. Historically, female and minority students have not pursued course work and careers in technology-rich fields. The AiS program has actively pursued a curriculum rich in gender and race equity to dispel negative feelings that students have for technical courses. Female and minority students are less likely to feel successful in classes where lecture and large group discussions are the primary means of learning. AiS has met this issue through small group and individual work opportunities. Female and minority mentors and teachers also help to encourage students to a higher level of achievement in science. 
All students are more likely to succeed in a hands-on minds-on environment. This is the environment envisioned by the initiators of the AiS program and achieved by all those involved in its growth and development. Through problem solving activities that involve real life problems that must be solved with collaboration, guidance from the teacher and a mentor, discussion among team members, and application to their problem at hand, students are able to enjoy the real-world environment of a scientific research laboratory in their day to day science investigations at school. Working in this type of atmosphere leads to an heightened level of critical and logical thinking skills. What a rich opportunity for success!

\section{References}

1. National Research Council, National Science Education Standards, (1996), Washington D.C.; National Academy Press.

2. Ziebarth, J. \& Carruth, S. (1992), Technology in the Classroom, K-12 Computational Science in Alabama. Alabama Journal of Mathematics, 16(1/2).

3. Honey, M., McMillan, K., Tsikalas, K. \& Grimaldi, C. (1995), Adventures in Supercomputing 1993-1994 Evaluation Final Report, (Center for Children and Technology Reports Issue 1). New York: Center for Children and Technology/Educational Development Center.

4. Honey, M., McMillan, K., Tsikalas, K. \& Light, D. (1996), Adventures in Supercomputing 1994-1995 Evaluation Final Report, (Center for Children and Technology Reports Issue 2). New York: Center for Children and Technology/Educational Development Center.

5. Newport, A., \& Kelly, J. (1997),Application of Heat Transfer, 1997 Tennessee AiS Expo report. URL: http://www.krellinst.org/AiS/national 